\section{International Scientific Journal Theoretical \& Applied Science}

\author{
p-ISSN: 2308-4944 (print) e-ISSN: 2409-0085 (online) \\ Year: $2015 \quad$ Issue: $01 \quad$ Volume: 21 \\ Published: $30.01 .2015 \quad$ http://www.T-Science.org
}

Gleb O. Akhramenko student,

Financial University under the Government of the Russian Federation (Kaluga Branch), Russia Gleb315@yandex.ru

SECTION 31. Economic research, finance, innovation, and risk management.

\title{
MEASURES TO IMPROVE THE QUALITY OF PUBLIC AND MUNICIPAL FINANCE
}

Abstract: The article presents measures to improve the quality of public and municipal finance on the basis of the analyzed statistical indicators for 2011-2013. In addition, their impact on the financial and credit system as a whole.

Key words: public finance, budget, fiscal policy, municipal finance, economic policy.

Language: Russian

Citation: Akhramenko GO (2015) MEASURES TO IMPROVE THE QUALITY OF PUBLIC AND MUNICIPAL FINANCE. ISJ Theoretical \& Applied Science $01 \quad$ (21): 64-67. doi: http://dx.doi.org/10.15863/TAS.2015.01.21.10

\section{МЕРЫ ПО УЛУЧШЕНИЮ КАЧЕСТВА УПРАВЛЕНИЯ ГОСУДАРСТВЕННЫМИ И МУНИЦИПАЛЬНЫМИ ФИНАНСАМИ}

Аннотация: В статье представлены меры по улучшению качества управления государственными и муниципальными финансами на основании проанализированных статистических показателей за 2011-2013 годы. Кроме этого, определено их влияние на финансово-кредитную систему в целом.

Ключевые слова: государственные финансы, бюджет, бюджетная политика, муниципальные финансы, экономическая политика.

Исходя из федеративного устройства Российской Федерации, государственные финансы включают в себя два уровня: финансы федеральных органов власти и финансы органов субъектов РФ. Что касается муниципальных финансов, то они являются низовым звеном и выделены в самостоятельный структурный уровень.

Основными источниками доходов консолидированного бюджета, как и прежде, остаются налоговые поступления, страховые взносы на социальное страхование и внешнеэкономическая деятельность государства. Среди налогов наибольший удельный вес занимают НДФЛ - 2499,05 млрд. руб. в 2013 году, налог на добычу полезных ископаемых 2575,78 млрд. руб., НДС - 1868,50 млрд. руб., налог на прибыль организаций - 2071,89 млрд. руб. Величина таможенных сборов от экспортируемой и импортируемой продукции составила 4057,92 млрд. руб. за период 2013 года.
Сравнивая объем налоговых поступлений в 2011-2013 годах, хочется отметить, что значительных колебаний в величине доходов не происходило, однако роль некоторых федеральных налогов в общем объеме налоговых поступлений постепенно увеличивается. Примерами могут служить НДФЛ, величина которого увеличилась более чем на $25 \%$ в 2013 году по сравнению с 2011, а также акцизы по подакцизным товарам. Объем этих налогов за последние два года вырос на 57,7\%.

Анализ показывает, что наибольший вес в структуре расходов бюджета занимают социальная политика, национальная оборона и образование. Хочется отметить, что, несмотря на увеличение доли расходов в структуре консолидированного бюджета, в России попрежнему существует множество направлений, которым должно уделяться пристальное внимание со стороны государства. В этих условиях особую важность играют мероприятия, 
направленные на повышение эффективности расходов бюджетов бюджетной системы РФ.

Более того, как показало проведенное ранее исследование (применительно к государственным финансам на региональном уровне), в Калужской области за период 2008-2012 годов государственный долг на душу населения вырос вдвое - с 8,39 тыс. рублей до 16,37 тыс. рублей $[3$, c.221]. В то же время, как показала проведенная рейтинговая оценка субъектов РФ по уровню риска несбалансированности региональных бюджетов, Калужская область в группе риска «выше среднего» [4, с.108].

Исходя из имеющихся проблем, необходимо предложить ряд рекомендаций, направленных на их решение. Разберем решение каждой из проблем в отдельности.

1. Отсутствие устойчивости и несбалансированность федерального бюджета [1; c. 13,14$]$.

Первостепенной мерой, призванной обеспечить долгосрочную устойчивость всей бюджетной системы РФ и противодействие бюджетным рискам должно стать применение механизма ограничения роста расходов федерального бюджета, а также восстановление достаточных объемов резервов.

Для обеспечения долгосрочной сбалансированности и устойчивости федерального бюджета необходимо реализовать комплекс мер по следующим основным направлениям.

- разработка и реализация бюджетной стратегии Российской Федерации. Бюджетная стратегия РФ - это документ, который включает в себя долгосрочный прогноз основных параметров бюджетной системы РФ, факторов и условий формирования и реализации основных направлений бюджетной политики, основных параметров финансового обеспечения государственных программ РФ с учетом целей, параметров, условий социально-экономического развития РФ в долгосрочном периоде.

- стабилизировать законодательно закрепленные "бюджетные правила" использования нефтегазовых доходов, регулирующих определение предельного объема расходов федерального бюджета. Как показывает практика последних лет, политика создания резервов полностью оправдала себя. Достаточно вспомнить 2009 год, когда средства Резервного фонда были использованы в целях финансирования дефицита федерального бюджета. Кроме того, наличие резервов стало важнейшим фактором минимизации роста долговых обязательств федерального бюджета, инвестиционной привлекательности страны и снижения стоимости государственных и корпоративных заимствований.

- поддержание безопасных уровня и структуры государственного долга Российской Федерации. В современных условиях благоприятная макроэкономическая ситуация в стране дает возможность осуществлять государственные заимствования на оптимальных условиях. Однако же при развитии кризиса в мировой экономике условия заимствований на долговых рынках для РФ значительно ухудшатся. В худшем случае возникнет возможность фактического закрытия долгового рынка, что не позволит привлечь нужного объема средств на приемлемых условиях. В данной ситуации средства Резервного фонда смогут гарантировать исполнение принятых на себя расходных обязательств федерального бюджета.

Сохраняющаяся зависимость федерального бюджета от внешнеэкономической конъюнктуры и достаточно высокий уровень рисков для бюджетной системы Российской Федерации требуют соблюдения более жестких ограничений объема долговой нагрузки. В условиях существования риска увеличения дефицита федерального бюджета, необходимой мерой является также разработка основных направлений долговой политики.

В целом политика государственных заимствований должна исходить из необходимости поддержания на приемлемом уровне объема государственного долга Российской Федерации, что позволит обеспечить устойчивость федерального бюджета.

2. Проблема низкой эффективности бюджетных расходов. Как уже отмечалось, основным инструментом повышения их эффективности станет развитие государственных и муниципальных программ. Чтобы решить проблемы, а также снять сложившиеся ограничения на всех уровнях управления при их формировании, предполагается осуществление следующих предложений [1; с. 31-33]:

- осуществление перехода на федеральном уровне, так и на регио Для этого важно разработать методические рекомендации о создании долгосрочного прогноза социально-экономического развития и бюджетных стратегий субъектов РФ, что должно способствовать объединению государственных и муниципальных программ в единую систему стратегического планирования в среднесрочной перспективе. Важной предпосылкой для этого может стать установление «потолков» расходов по каждой из программ на полный срок ее реализации. Они дают возможность определить приоритеты в распределении бюджетных 
ассигнований, а также создать стимулы для ответственных исполнителей государственных и муниципальных программ по выявлению и использованию резервов для перераспределения и повышения уровня эффективности использования бюджетных средств.

- расширение прав ответственных исполнителей государственных и муниципальных программ в целях повышения степени их финансовой самостоятельности. С целью реализации данного направления необходимо провести закрепление полномочий ответственных исполнителей государственных и муниципальных программ в рамках бюджетного процесса как на стадии формирования проекта закона о бюджете, так и на стадии исполнения бюджета с возможностью внесения изменений в соответствующие нормативные правовые акты в случае необходимости.

- формирование общих подходов к увязке государственных программ субъектов РФ с соответствующими государственными программами РФ в целях повышения качества государственных программ субъектов РФ. Для этого целесообразным является проведение корректировки уже утвержденных государственных программ РФ, в которых реализуются полномочия по предметам совместного с субъектами РФ ведения, с целью более полного отражения участия регионов в достижении целей соответствующих государственных программ Российской Федерации.

- завершение работы по сокращению объема субсидий из федерального бюджета в рамках государственных программ России бюджетам субъектов РФ в среднесрочной перспективе. Успешная реализация этой меры позволит уменьшить число административных процедур, которые сопровождают предоставление субсидий при заключении единого соглашения.

- соответствие сроков обработки и представления статистических данных, с помощью которых рассчитываются показатели государственных программ РФ, срокам проведения оценки эффективности реализации государственных программ РФ и формирования проекта Ф3 о федеральном бюджете на очередной финансовый год и плановый период.

Решение проблемы предполагает внесение корректировок в Федеральный план статистических работ, которые смогли бы обеспечить формирование наиболее приоритетных показателей реализации государственных программ РФ. Также, в целях обеспечения возможности оперативных корректировок хода реализации указанных государственных программ важно расширить перечень статистических показателей, которые формируются на ежеквартальной и ежемесячной основе и обеспечивают основу для принятия управленческих решений.

3. Устаревание системы межбюджетных отношений. Как было отмечено в главе 2, за прошедшие несколько лет Калужской области удалось достичь серьезных экономических результатов. Трудности, с которыми пришлось столкнуться региону, обострили проблему межбюджетных отношений и со всей очевидностью продемонстрировали необходимость разработки принципиально новой концепции развития межбюджетных отношений в Российской Федерации. На основе опыта региона можно сформулировать некоторые рекомендации, направленные на устранение основных проблем данной экономической категории [2; с. 3].

- пересмотр системы предоставления межбюджетных трансфертов. Чтобы достичь положительного экономического эффекта, необходима, во-первых, значительная мотивация регионов и муниципальных образований, что, в свою очередь, помогло бы решить проблему быстрого экономического роста. В современных условиях регионы пока что не заинтересованы в достижении благоприятного инвестиционного эффекта. Проблема заключается в том, что привлекая значительные ресурсы под инвестиционные проекты, с ростом доходов от вновь созданных производств происходит прямо пропорциональное снижение и объема предоставляемых трансфертов. В данных условиях особую значимость имеет решение В. В. Путина о компенсации регионам части затрат, понесенных ими на создание инфраструктуры индустриальных парков.

- реализация мер по укреплению самостоятельности и сбалансированности местных бюджетов. В этой связи целесообразно передать в распоряжение местных бюджетов те налоговые доходы, на собираемость которых могут влиять в большей степени именно органы местного самоуправления. Примером может служить передача муниципальным образованиям налога, взимаемого на территории Калужской области в связи с применением упрощенной системы налогообложения, хоть это и не предусмотрено Бюджетным кодексом РФ.

- повышение самостоятельности органов местного самоуправления путем передачи в распоряжение местных органов транспортного налога, доходы от которого в настоящий момент поступают в бюджет субъекта. Данное мероприятие дало бы возможность значительно 
расширить доходные источники местных дорожных фондов.

- расширение полномочий органов власти субъектов РФ по законодательному регулированию межбюджетных отношений и определению элементов налогообложения. Меры в этой области способствовали бы укреплению доходной базы и принятию сбалансированных экономических решений.

Итак, обобщая все вышесказанное, можно заключить, что на данном этапе экономического развития в Российской Федерации существуют некоторые проблемы в управлении государственными и муниципальными финансами, которые отрицательным образом сказываются на состоянии всей кредитнофинансовой системы. Реализация здравых государственных мероприятий, в том числе раскрытых выше, будет способствовать сбалансированному развитию всей бюджетной системы и решению тех проблемных вопросов, которые имеют место в современных условиях.

Научное исследование проведено под руководством кафедры - «Финансы и кредит», Калужский филиал Финансового университета при Правительстве Российской Федерации, Россия.

\section{References:}

1. (2013) Programma povyisheniya effektivnosti upravleniya obschestvennyimi (gosudarstvennyimi i munitsipalnyimi) finansami na period do 2018 goda, utverzhdena rasporyazheniem Pravitelstva RF ot 30.12.13. \# 2593-r

2. Baburin VS (2014) Opyit Kaluzhskoy oblasti pokazyivaet neobhodi-most razrabotki novoy kontseptsii razvitiya mezhbyudzhetnyih otnosheniy. Parlamentskaya gazeta. 25.03.2014. - pp. $2-3$.

3. Balyinin IV (2014) Kompleksnyiy analiz dolgovoy politiki $\mathrm{v}$ ramkah reytingovoy otsenki sub'ektov Rossiyskoy Federatsii po urovnyu riska nesbalansirovannosti regionalnyih byudzhetov. Ekonomika i predprinimatelstvo. 2014. \# 5-1. pp. 217-222.

4. Balyinin I (2014) Reytingovaya otsenka sub'ektov Rossiyskoy Federatsii po urovnyu riska nesbalansirovannosti regionalnyih byudzhetov (na osnove razrabotannoy modeli). RISK: Resursyi, informatsiya, snabzhenie, konkurentsiya. 2014. \# 3. pp. 104-109.

5. Balyinin IV (2013) Kompleksnaya otsenka sotsialno-ekonomicheskogo razvitiya Kaluzhskoy oblasti. Mirovoe soobschestvo: problemyi sotsialno-ekonomicheskogo i duhovno-politicheskogo razvitiya Sbornik nauchnyih statey Vserossiyskoy nauchno- prakticheskoy konferentsii. Finansovyiy universitet pri Pravitelstve RF (Novorossiyskiy filial); Pod redaktsiey L. S. Andriyanovoy. Penza, 2013. pp. 289-298.

6. Ryabova IS, Basova NV (2008) Byudzhetnoe finansirovanie otrasley sotsialnoy sferyi $v$ Rossiyskoy Federatsii. Audit i finansovyiy analiz. 2008. \# 3. pp. 256-259.

7. Ivanova IA, Murzaeva OV (2012) Kolichestvennyie parametryi sistemyi finansirovaniya zdravoohraneniya v Rossii. Nauchnoe obozrenie. 2012. \# 2. pp. 527-537.

8. Kayurov EA (2013) Konstitutsionno-pravovoe regulirovanie gosudarstvennyih (munitsipalnyih) finansov v Rossii. Pravo. Zhurnal Vyisshey shkolyi ekonomiki. 2013. \# 2. pp. 48-62.

9. Makarova SN (2013) Teoreticheskie aspektyi programmnogo byudzhetirovaniya $\mathrm{V}$ sfere gosudarstvennyih i munitsipalnyih finansov. Finansyi i kredit. 2013. \# 48. pp. 7-14.

10. Bolotin VV (2013) K voprosu o strukture tsentralizovannyih finansov. Finansovyiy biznes. 2013. \# 2 (163). pp. 63-69.

11. Sergeev L (2013) Problemyi regionalnogo gosudarstvennogo finansovogo menedzhmenta. Obschestvo i ekonomika. 2013. \# 10. pp. 112124. 